\title{
Correction to: When Might Heterosexual Men Be Passive or Compassionate Toward Gay Victims of Hate Crime? Integrating the Bystander and Social Loafing Explanations
}

\author{
Chuma Kevin Owuamalam $^{1}$ (D) . Andrea Soledad Matos ${ }^{2}$
}

Published online: 4 April 2020

๑) Springer Science+Business Media, LLC, part of Springer Nature 2020

\section{Correction to: Archives of Sexual Behavior https://doi.org/10.1007/s10508-019-01592-y}

The following errors were present in this article as originally published:

A question mark was missing from the end of the first sentence under the "General Discussion" section.

The fifth sentence in the "Theoretical Opportunities" section read (incorrectly):

This is because (1) the common-in-group bond is likely weakened as a result of the of lesbian women who are so inclined...

Instead of (correctly):

This is because (1) the common-in-group bond is likely weakened as a result of lesbian women who are so inclined...

In the last sentence in the "Theoretical Opportunities" section read (incorrectly):

So, although the current findings provide a promising start, future studies could aim to test the derived assumptions directly, by, for example, extending our propositions to reactions toward lesbians and transgendered victims of hate crime such studies could also examine reactions toward norm conforming versus norm-deviating heterosexual victims.

Instead of (correctly):

So, although the current findings provide a promising start, future studies could aim to test the derived assumptions directly, by, for example, extending our propositions

The original article can be found online at https://doi.org/10.1007/ s10508-019-01592-y.

Chuma Kevin Owuamalam

chuma.owuamalam@nottingham.edu.my

1 Division of Organizational and Applied Psychology, University of Nottingham Malaysia, Jalan Broga,

43500 Semenyih, Selangor, Malaysia

2 School of Psychology, University of Nottingham Malaysia, Semenyih, Selangor, Malaysia to reactions toward lesbians and transgendered victims of hate crime. Such studies could also examine reactions toward norm conforming versus norm-deviating heterosexual victims.

The original article has been corrected.

Publisher's Note Springer Nature remains neutral with regard to jurisdictional claims in published maps and institutional affiliations. 